\title{
NOTICIAS ACADEMICAS
}

\section{Proyectos Pedagógicos}

Luis Evelio Vanegas Rubio

Programa de Lenguas Modernas

A través del Comité de Práctica Docente se encuentran en estudio dos grandes proyectos -dependientes entre sí-y cuya realización conllevaría cambios fundamentales en la ejecución de la práctica docente en todos los programas de la Facultad.

El primer proyecto tiene que ver con la creación de un colegio que sea el centro de Aplicación Pedagógica de la Facultad. El segundo es una consecuencia directa y se trata de la necesidad de adecuar el reglamento de práctica para poder cumplir de manera óptima con el compromiso que se adquiera con el citado colegio.

El origen de este proyecto de crear un colegio para que sea el Centro de Aplicación Pedagógica, surge de la solicitud que los profesores de la jornada de la tarde de la Escuela Agustín Codazzi (barrio Timanco) hicieron a la Universidad para que ésta enviara practicantes y así poder ellos ofrecer los grados 6o, 7o, 80. y 9o. Se iniciaron los contactos con visitas al plantel y reuniones con directivos y profesores junto con el Jefe de Núcleo, consultas a la Secretaría de Educación y reuniones con participación de representantes del profesorado del colegio, el Decano de la Facultad de Educación y el suscrito como representantes de la Universidad Surcolombiana.

Los objetivos fundamentales de la creación de este colegio se pueden resumir en dos puntos:

1. Solucionar un problema social en el área de la educación de la zona sur de la ciudad de Neiva (Núcleo Educativo No.6, barrio Timanco) en donde el déficit de cupos para la educación secundaria es sensible y requiere solución pronta y efectiva, so pena de seguir exponiendo a una gran cantidad de niños a la vagancia y sus negativas sociales, por falta de cupos.

2. Crear un Centro de Aplicación Pedagógica de la Facultad de Educación de la Universidad Surcolombiana, en donde, además de aportar soluciones concretas al problema educativo del municipio, se puedan aplicar principios que generen cambios positivos en la secundaria e innovaciones educativas nacidas al interior de cada programa académico en busca de una mayor cualificación tanto en la formación de docentes como en los educandos.

Los parámetros sobre los cuales está girando la propuesta se pueden resumir así:

1. Se transforma la escuela Agustín Codazzi en un colegio oficial que ofrecerá los niveles de primaria y básica secundaria en la modalidad de Bachillerato Académico o Clásico.

2, El propietario del plantel será el Municipio de Neiva, para lo cual se deben realizar los trámites necesarios a través de Secretaría de Educación, del Consejo, Alcaldía y demás entidades pertinentes.

3. La planta física será la misma en donde funciona en la actualidad la Escuela Agustín Codazzi, las ampliaciones y dotación necesaria estarán a cargo del Municipjo.

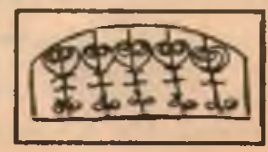


4. La Universidad Surcolombiana se compromete a plancar y desarrollar las asignaturas abajo enumeradas, en los cursos 60, 7o, 80, y 9o, con los "PRACTICANTES" de los diferentes PROGRAMAS ACADEMICOS ofrecidos en la Facultad de Educación. Además se compromete a enviar practicantes en esas mismas asignaturas para algunos cursos de la educación básica primaria de ese plantel. Las asignaturas a cargo de la Universidad Surcolombiana serán:

- Sexto grado: Español - Idioma extranjero - Aritmética y Geometría, Educación Física y Educación Estética.

- Sćptimo grado: Español, Idioma Extranjero, Aritmética y Geometría, Educación Física y Educación Estética. Octavo grado: Español, Idioma Extranjero, Algebra y Geometria, Educación Física y Educación Estética.

- Noveno grado: Español, Idioma Extranjero, Algebra y Geometria, Educación Física y Educación Estética.

Además el Programa de Administración Educativa se encargará de la asesoría de la plancación y desarrollo específico.

5. Los movimientos académicos internos que surjan a raíz de este proyecto, se harán respetando los derechos de los profesores, el estatuto docente y buscando siempre la mejor utilización del recurso humano existente en la escuela Agustin Codazzi.

6. El Municipio de Neiva se compromete a cubrir los docentes de las asignaturas faltanttes (Historia, Geografía, Vocacionales y Técnicas y Caligrafía) asi como también nombrar los docentes jefes de Programa del colegio quienes con los ascsores de Práctica de cada Programa dc la Universidad Surcolombiana, coordinarin el desarrollo de las asignaturas y demás actividades escolares.

El nombramiento de las directivas del nuevo colegio lo hará el Municipio con participación directa de la Universidad Surcolombiana, buscando la excelencia académica.

7. El Municipio cubrirá además la planta administrativa necesaria: Secretario, Pagador, Médico, etc.

\section{Repercusiones para la} realización de la práctica. docente de la facultad

Para poder dar cumplimiento a los compromisos que la Universidad Surcolombiana adquiera con la creación de este colegio, se hace necesario establecer claras responsabilidades al interior de cada programa y cambiar algunos aspectos del reglamento de práctica docente. Las más relevantes son:

1. La responsabilidad de la calidad de educación que se ofrezca en el Centro de Aplicación Pedagógica será de cada uno de los Programas Académicos que se ofrezcan en la Facultad de Educación de la Universidad Surcolombiana.

2. Las innovaciones pedagógicas y actividades de investigación que se ejecuten en ese plantel deberán ser analizadas, $y$ aprobadas al interior de cada programa y cuando sea necesario por el Comité de Práctica de la Facultad.

3. El reglamento de Práctica deberá cambiarse en tal forma que ella se realice por todos y cada uno de los practicantes en un periodo escolar completo, es decir, de enero 19 a junio 15 y de julio 19 a noviembre 30 , respondiendo así el practicamente, en forma integral, a todus las obligaciones escolares.

Por motivos de brevedad me abstengo de entrar en detalles en este escrito, pero espero que sea útil esta información y ayude a impulsar esta solución a la comunidad y a la Universidad Surcolombiana. 